\title{
New evidence for the non-infectivity of Treponema pallidum for mice
}

\author{
R. F. SCHELL, D. M. MUSHER, K. JACOBSON, AND P. SCHWETHELM \\ From the Department of Microbiology and Immunology and the Department of Medicine (Infectious \\ Disease Section), Baylor College of Medicine, and the Veterans Administration Hospital, Houston, \\ Texas 7703I, U.S.A.
}

After many years of research the question whether Treponema pallidum is infective for the mouse is still unanswered (Gueft and Rosahn, 1948; Rosahn, Gueft, and Rowe, 1948; Rosahn and Rowe, 1950a, b; Rosahn, 1952). Although virulent treponemes can be recovered from the tissues of mice at least 6 months after injection (Rosahn and others, 1948; Rosahn, 1952; World Health Organization, 1970), two lines of evidence have suggested that mice are not truly infected by this organism:

(1) There is no histological evidence of disease (Gueft and Rosahn, 1948; Rosahn and others, 1948);

(2) VDRL antibodies do not develop (World Health Organization, 1970) and the appearance of treponemal immobilizing antibodies is greatly delayed (Gastinel, Collart, Hamelin, Vaisman, and Dunoyer, 1958; Thivolet, Monier, Sepetjian, and Salussola, 1969).

On the other hand Rosahn (1952) reported an apparent shortening of the life-span of mice inoculated with $T$. pallidum and Ohta (1972) has recently used fluorescent antibody and microhaemagglutination techniques to demonstrate that antitreponemal antibodies appear within 2 weeks after mice are challenged with $T$. pallidum. Ohta took this finding to support the concept that $T$. pallidum is infectious for this species.

We have recently shown that syphilitic rabbits are resistant to challenge with Listeria monocytogenes and have suggested that this resistance occurs because infection with $T$. pallidum stimulates cell-mediated immunity (CMI) (Schell and Musher, 1974). Resistance could be transferred using thymus-dependent cells obtained from syphilitic rabbits (Schell and Musher, in press). We were motivated to repeat these studies in mice because enhancement of CMI (Blanden, Lefford, and Mackaness, 1969; Mackaness, 1964) usually reflects an active infection (Blanden

Received for publication April 30, 1974

Address for reprints: Daniel M. Musher, M.D., Venereal Disease Research Laboratory, Building 203, VA Hospital, Houston, Texas 77031.

This work was supported by General Research Funds, VA Hospital, Houston and by NIH Grants 1 RO1 AI 11305 and TO 1 AI 00374. and others, 1969; Mackaness, 1964; Mackaness, Blanden, and Collins, 1966; Mackaness and Blanden, 1970) and proof of infectivity for the mouse would greatly facilitate studies of the immunology of syphilis.

In this paper we present evidence that activation of CMI does not occur when mice are inoculated with $T$. pallidum; we infer from these data that this virulent treponeme is not infective for the mouse.

\section{Material and methods}

MICE

Four week-old female CF-1 mice weighing 18-25 g. were obtained from Carworth Farms, Portage, Michigan. The mice were housed five or six to a cage and fed mousefood pellets and water.

TREPONEMA PALLIDUM (Nichols strain)

This virulent treponeme was obtained from the Center for Disease Control, Atlanta, Georgia. Orchitis regularly developed in rabbits 9 to 14 days after intratesticular injection with $10^{6}-10^{7}$ organisms. Inflamed testes were removed aseptically, minced in $6 \mathrm{ml}$. sterile saline, and ground with a mortar and pestle. After centrifugation at $270 \mathrm{G}$. for $3 \mathrm{~min}$. to remove gross cellular debris, treponemes in the supernatant were counted under darkfield microscopy; the average yield was $10^{7}-10^{8}$ organisms per ml. Suspensions of $T$. pallidum obtained in this fashion were used to inoculate mice intraperitoneally (IP). Control mice were inoculated with a suspension that had been prepared from non-infected rabbit testes. No more than 1 hour elapsed between removal of treponemes from testes and inoculation into mice. $T$. pallidum was regularly recovered from the axillary and inguinal lymph nodes of mice inoculated 60 days previously.

\section{LISTERIA MONOCYTOGENES}

Listeria was isolated from a patient with meningitis and passed five times in mice. A standard inoculum for use in all challenges was prepared as follows:

A single colony was inoculated into brain heart infusion broth (BHI). After incubation for $16 \mathrm{hrs}$ at $37^{\circ} \mathrm{C}$., the culture was centrifuged at $10,000 \mathrm{G}$. for $20 \mathrm{~min}$. at $4^{\circ} \mathrm{C}$.; the bacterial pellet was washed, re-centrifuged, and resuspended in BHI broth. This suspension was homogenized and filtered through a $45 \mu$ membrane filter to 
remove clumps of bacteria. Samples containing $3 \times 10^{9}$ colony-forming units of Listeria per $\mathrm{ml}$. were distributed into vials, sealed, and stored at $-70^{\circ} \mathrm{C}$. No loss in viability of the stored suspensions has been noted over a 19 month period.

\section{INFECTING MICE WITH LISTERIA}

Non-specific enhancement of CMI has been assayed by comparing the number of Listeria that could be recovered from the livers and spleens of vaccinated and nonvaccinated mice after intravenous (IV) challenge with this organism (Mackaness, 1961, 1964). This comparison, which presumably measures listericidal activity of macrophages in vivo (Blanden and others, 1969; Mackaness, 1964), is usually made 24 to $48 \mathrm{hrs}$ after challenge, because after this time even the nonvaccinated animals will have developed an immune response to Listeria (Mackaness, 1961, 1964).

Accordingly, at varying time periods after inoculation with $T$. pallidum mice were challenged IV with 2-3 $\times 10^{4}$ Listeria. Forty-eight hours later they were asphyxiated with ether. Livers and spleens were removed aseptically and homogenized in saline with teflon-glass homogenizers. The homogenates were diluted serially and aliquots plated on BHI agar. Colonies were counted after 16-18 hours incubation at $37^{\circ} \mathrm{C}$. Data are reported as $\log _{10}$ of the number of Listeria per liver or per spleen.

RANDOMIZATION OF ANIMALS

All mice were randomly selected for infection, challenge and sacrifice.

\section{STATISTICAL ANALYSIS}

The analysis of variance was used. Fischer's Least Significant Difference test (Steel and Torrie, 1960) was used to examine pairs of means when a significant F-ratio indicated reliable mean differences. The alpha level was set at 0.05 before the start of the experiments.

\section{Results}

The Fate of IV Listeria in mice inoculated with $\mathrm{T}$. pallidum

The purpose of this experiment was to determine if the growth of Listeria was inhibited in the livers and spleens of mice inoculated with $T$. pallidum. 52 mice were inoculated IP with $4 \times 10^{7} \mathrm{~T}$. pallidum; 52 control mice received an extract of normal rabbit testes. At 4-day intervals thereafter, four mice from each group were infected IV with 2-3 $\times 10^{4}$ Listeria. These animals were killed $48 \mathrm{hrs}$ later and the number of Listeria in the tissues was determined.

No difference was detected in the number of Listeria recovered from the livers or spleens of mice inoculated with $T$. pallidum when compared to controls (Figs 1 and 2). This experiment was repeated twice, again with negative results.

Effect of re-inoculation with $\mathrm{T}$. pallidum on the growth of Listeria

The purpose of this experiment was to determine whether a second inoculation with $T$. pallidum

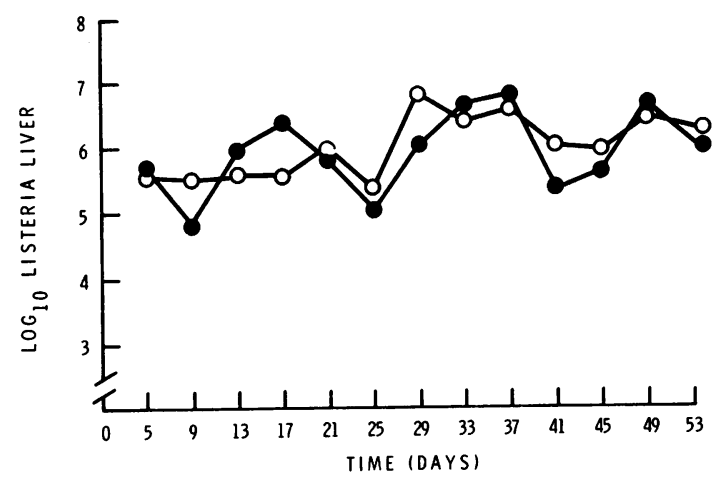

FIG. 1 Growth of Listeria in the livers of control mice $(\mathrm{O}-\mathrm{O})$ and mice inoculated with Treponema pallidum ( - ). The standard error associated with each mean was 0.45 . There were four mice per group at each time interval

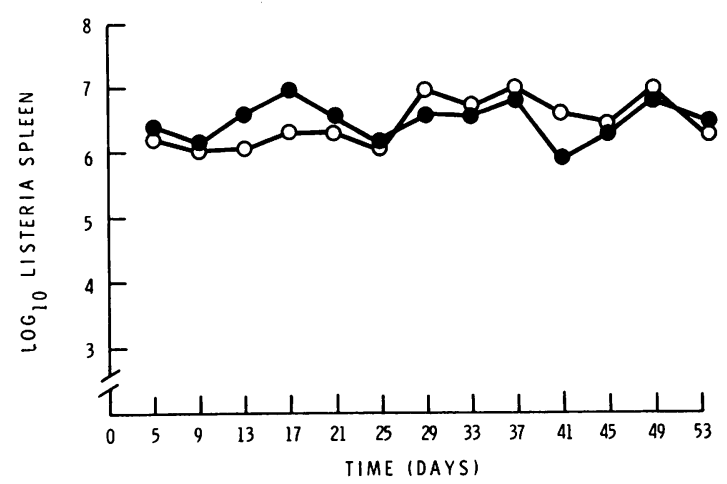

FIG. 2 Growth of Listeria in the spleens of control mice $(\mathrm{O}-\mathrm{O})$ and mice inoculated with Treponema pallidum (-) . The standard error associated with each mean was $0 \cdot 28$. There were four mice per group at each time interval

would induce listericidal activity which was not detected after the first inoculation. 7 weeks after having received the first injection of treponemes, 44 mice were re-inoculated IP with $4 \times 10^{7} \mathrm{~T}$. pallidum, and 44 control mice received a second inoculation of normal rabbit testicular suspension. Beginning 4 days later and at 4-day intervals thereafter, four syphilitic and control mice were infected with Listeria and killed $48 \mathrm{hrs}$ later. No difference was detected in the number of Listeria recovered from the livers and spleens of syphilitic mice when compared to control mice.

Fate of IV Listeria in mice inoculated with $\mathrm{T}$. pallidum and subsequently challenged with $\mathrm{T}$. refringens

Since enhanced CMI may be dependent upon continued availability of antigen (Blanden and others, 
1969), an attempt was made to stimulate CMI by injecting syphilitic mice with $T$. refringens, an avirulent treponeme which appears to share common antigens with $T$. pallidum (Dupouey, 1963a, b) and which can be isolated in much greater numbers than virulent treponemes. At 4-day intervals after inoculation with $T$. pallidum and sequentially thereafter groups of syphilitic mice were challenged with $10^{9} \mathrm{~T}$. refringens; $96 \mathrm{hrs}$ later they were infected with Listeria and killed as in previous experiments.

Control groups for this study included mice that received:

(1) Normal testes and T. refringens;

(2) Normal rabbit testes;

(3) Only $T$. pallidum.

The number of Listeria detected in livers and spleens was the same for mice from each of the four experimental groups.

\section{Discussion}

Suppression of the growth of Listeria monocytogenes was not detected in mice inoculated with Treponema pallidum. This is in contrast to observations on the course of syphilitic infection in rabbits in which enhanced ability to suppress the growth of Listeria in the liver was detected 3, 4, and 5 weeks after infection with $T$. pallidum (Schell and Musher, 1974). A second injection of $T$. pallidum at a time when suppression was beginning to wane greatly prolonged the listericidal activity. Suppression of the growth of Listeria in syphilitic rabbits (Schell and Musher, 1974) gave indirect support that cellmediated immunity is activated; no such evidence was obtained in the case of mice.

Non-specific resistance to Listeria has been shown to be dependent upon activated macrophages (Blanden and others, 1969; Mackaness, 1964) and also on the availability of the specific inducing antigen (Blanden and others, 1969; Lefford, 1971). It is possible that failure to detect enhanced nonspecific resistance to Listeria in mice inoculated with $T$. pallidum may be related to the amount of treponemal antigen available to the immune system. That this is not the case was suggested by our observations that neither a second injection of $T$. pallidum nor inoculation with a much larger number of $T$. refringens after an initial injection of $T$. pallidum increased the ability of mice to suppress the growth of Listeria.

The studies reported herein utilize relatively new concepts to support an old theory, namely that $T$. pallidum is not infective for mice. Although Ohta (1972) has shown that mice respond with antibody production to IP injections of $10^{6} \mathrm{~T}$. pallidum, his studies did not include, as a control, mice that were injected with equal numbers of killed $T$. pallidum. The antibodies he observed may have resulted from antigenic challenge with a foreign substance; their appearance does not necessarily reflect an infectious process.

\section{Summary}

We have recently shown that syphilitic rabbits are resistant to challenge with Listeria monocytogenes. This resistance was thought to reflect stimulation of cell-mediated immunity by active infection with Treponema pallidum. We now report data which show that the growth of Listeria was not suppressed in mice inoculated with $T$. pallidum. Re-inoculation with $T$. pallidum or with a large dose of an avirulent treponeme also failed to suppress the growth of Listeria. These results contrast with those obtained in rabbits and provide additional evidence that $T$. pallidum is not infective for the mouse.

Our thanks are due to Susan Ramsey for expert technical help and to Helen Bremner for secretarial assistance.

\section{References}

Blanden, R. V., LefFord, M. J., and Mackaness, G. B. (1969) F. exp. Med., 129, 1079

Dupouky, P. (1963a) Ann. Inst. Pasteur, 105, 725

- (1963b) Ibid., 105, 949

Gastinel, P., Collart, P., Hamelin, A., Vaisman, A., and Dunoyer, F. (1958) Ann. Derm. Syph., 85, 497

Gueft, B., and Rosahn, P. D. (1948) Amer. F. Syph., 32,59

LEFFORD, M. J. (1971) Immunology, 21, 369

MACKANESS, G. B. (1961) f. exp. Med., 116, 381 (1964) Ibid., 120, 105

- and Blanden, R. V. (1970) 'Cellular immunity', in 'Infectious Agents and Host Reactions', ed. S. Mudd, p.22. Saunders, Philadelphia

- - , and Collins, F. M. (1966) f. exp. Med., 124,573

OHTA, Y. (1972) F. Immunol., 108, 921

Rosari, P. D. (1952) Arch. Derm. Syph., 66, 547

-, GuefT, B., and Rowe, C. L. (1948) Amer. f. Syph., 32, 327

- and Rowe, C. L. (1950a) Ibid., 34, 40

- - (1950b) Ibid., 34, 167

Schell, R. F., and MUSHER, D. M. (1974) Infect. and Immun., 9, 658

- (in press) $\mathcal{F}$. Immunol.

Steel, R. G. D., and Torrie, J. H. (1960) 'Principles and Procedures of Statistics'. McGraw-Hill, New York

Thivolet, J., Monier, J. C., Sepetjian, M., and SalusSOLA, D. (1969) Experientia (Basel), 25, 304

World Health ORganization (1970) 'Treponematoses Research'. Technical report no. 455, W.H.O., Geneva 